\title{
PREVENÇÃO E ENFRENTAMENTO SUPRANACIONAIS À CORRUPÇÃO: REFLEXÕES SOBRE A ATUAÇÃO DO ORGANISMO EUROPEU DE LUTA
}

\author{
ANTIFRAUDE
}

\author{
Heron de Jesus Garcez Pinheiro ${ }^{1}$ \\ Roberto Carvalho Veloso ${ }^{2}$
}

\begin{abstract}
RESUMO: Este artigo objetiva analisar a atuação supranacional do Organismo Europeu de Luta Antifraude (OLAF) no âmbito da União Europeia, através de revisão bibliográfica e estudo do direito comunitário. Discorre-se sobre a compreensão científica da corrupção a partir das teorias que a referenciam, apontando-se os instrumentos convencionais de prevenção e enfrentamento. Em seguida, expõe-se o impacto da fraude nas finanças da União Europeia, a justificar a necessidade de fortalecimento do OLAF. Enfatiza-se a disciplina dos inquéritos e examinam-se os balanços e resultados das atividades daquela instituição.
\end{abstract}

Palavras-Chave: Direito Internacional; União Europeia; OLAF; Corrupção; Enfrentamento Supranacional.

\section{SUPRANATIONAL PREVENTION AND FIGHTING AGAINST CORRUPTION: REMARKS ON EUROPEAN ANTI-FRAUD OFFICE'S PERFORMANCE}

\begin{abstract}
This article aims to analyze the supranational performance of the European Anti-Fraud Office (OLAF) in the scope of European Union, through bibliographical review and study of community law. We discuss the scientific understanding about corruption as from the theories that refer to it, pointing at conventional anti-corruption instruments, preventive and repressive measures. Afterwards, the impact of fraud on the finances of the European Union in exposed, justifying the need to strengthen OLAF. We emphasize the discipline of the investigations, balances and results on the activities of that institution.
\end{abstract}

Keywords: International Law; European Union; OLAF; Corruption; Supranational Fighting.

\footnotetext{
1 Mestre em Direito pelo Programa de Pós-Graduação em Direito e Instituições do Sistema de Justiça da Universidade Federal do Maranhão (PPGDIR/UFMA). Advogado. Procurador do CREA-MA. E-mail: herongarcez@ hotmail.com.

${ }^{2}$ Doutor e Mestre em Direito pela Universidade Federal de Pernambuco (UFPE). Professor Associado da Universidade Federal do Maranhão (UFMA). Juiz Federal. Membro da Comissão de Juristas do Senado Federal encarregada da elaboração do Novo Código Eleitoral. E-mail: velosorc@uol.com.br.
} 


\section{INTRODUÇÃO}

Os devastadores escândalos de corrupção nas instâncias governamentais e administrativas constituem tema de grande preocupação da opinião pública internacional nos primeiros lustros do século XXI, a retratar a persistência - em larga escala - de comportamentos patrimonialistas de agentes públicos no seio dos Estados Nacionais e com articulações transfronteiriças, não raro estruturados em verdadeiras organizações criminosas.

A Transparência Internacional, organização não-governamental germânica instituída no início da década de 1993 para estudar o fenômeno sócio-político da corrupção, através de índices obtidos mediante colheita de dados junto a analistas, empresários, usuários de serviços e a população em geral, divulga periodicamente o Índice de Percepção da Corrupção (Corruption Perception Index).

A reputação do Brasil nas séries dos rankings destinados a aferir a corrupção entre as nações tem sido assaz insatisfatória. No ano de 1999, o Brasil ocupou a $45^{\text {a }}$ posição no Índice de Percepção da Corrupção (CPI), com nota 41. Em 2009, uma década após, o país despencou para a $75^{\text {a }}$ posição logrando a nota 37 (GARCIA; ALVES, 2014).

Na edição do Índice de Percepção da Corrupção de 2016, o Brasil ocupou a 79a posição (nota 40), com pioras de posição e nota em relação à edição anterior da medição (TRANSPARENCY INTERNATIONAL, 2016). E no CPI/2017, vislumbrou-se vertiginosa queda para a $96^{\mathrm{a}}$ posição (nota 37). Consoante aludido indicador, os países com as melhores notas, reputados os mais transparentes e menos corruptos do mundo, são Dinamarca, Finlândia, Suécia e Nova Zelândia, os quais têm se revezado nas primeiras colocações nas últimas décadas (TRANSPARENCY INTERNATIONAL, 2017).

Nesse diapasão, as inéditas cifras da Operação Lava Jato, constituída a partir de força-tarefa envolvendo Poder Judiciário, Ministério Público e Polícia Federal, até 13/09/2016, consubstanciam êxito indubitável do combate articulado à corrupção em salvaguarda ao patrimônio público: 1.397 procedimentos instaurados, 654 buscas e apreensões, 174 conduções coercitivas, 76 prisões preventivas, 92 prisões temporárias, 06 prisões em flagrante, 112 pedidos de cooperação internacional, 70 acordos de colaboração premiada, 06 acordos de leniência, 233 acusações criminais, 07 acusações de improbidade contra 38 pessoas e 16 empresas pleiteando ressarcimento no importe de $\mathrm{R} \$ 38,1$ bilhões, 
repatriação de $\mathrm{R} \$ 745,1$ milhões e bloqueio de $\mathrm{R}$ \$ 2,4 bilhões em bens dos réus (BRASIL, 2016).

Contudo, referidos esforços anticorrupção ainda constituem exceção da República Federativa do Brasil, diante da desorganização das instituições estatais para fazer face aos poderosos esquemas de assalto ao Erário. A cidadania ainda não se posiciona suficientemente vigilante na cobrança pela transparência da gestão dos recursos públicos e no combate à impunidade. Concorre para tal cenário a tradicional escassez de estudos acadêmicos concernentes à prevenção e enfrentamento da corrupção, bem como relativos à tutela da probidade administrativa, em níveis promocional e repressivo-punitivo.

Em termos pragmáticos formulam-se os seguintes problemas:a ocorrência da corrupção é exclusiva dos países em desenvolvimento e subdesenvolvidos? Quais perspectivas teórico-conceituais do referido fenômeno no tempo e espaço? Como os países europeus têm lidado com a questão, mormente no âmbito supranacional da União Europeia? Quais as lições que se pode extrair das articulações regionais e internacionais para tutela da integridade e probidade na gestão pública?

Sob tais perspectivas,objetiva-se destacar a relevância empírica de estudos comparados acerca da experiência supranacional de prevenção e enfrentamento à corrupção pelo Organismo Europeu de Luta Antifraude (OLAF), que detém atribuição exclusiva para realizar investigações, através de inquéritos, objetivando zelar pela regularidade dos fundos da União Europeia e a punição de eventuais transgressores.

O objetivo deste trabalho é apresentar uma proposta de resolução dessas controvérsias a partir de incursões mais aprofundadas na conceituação e nos marcos teóricos sobre corrupção, com ênfase para as teorias funcionalistas, da modernização e do neoinstitucionalismo econômico, centradas, respectivamente, nas concepções de desenvolvimento, patrimonialismo e rent-seeking.

Empregou-se a título de metodologia levantamento bibliográfico e estudo comparado do direito comunitário sobre estruturação institucional, prevenção e enfrentamento à corrupção, assinalando-se a escala planetária das preocupações e das medidas preventivas e repressivas, bem como pontuando aspectos reputados mais centrais da Convenção Interamericana contra a Corrupção (1996), da Convenção Relativa à Luta contra a Corrupção de Funcionários das Comunidades Europeias ou dos Estados-Membros da União Europeia 
(1997) e da Convenção das Nações Unidas contra a Corrupção (2003), com declinação dos demais diplomas multilaterais pertinentes à matéria.

Expõe-se o elevado impacto da corrupção e da fraude nas finanças da União Europeia, a justificar a instituição e o funcionamento regular do OLAF, cujos objetivos, finalidades e atribuições são abordadas. Menciona-se a norma disciplinadora da instauração de inquéritos, examinando-se criticamente, por derradeiro, os balanços com resultados acerca da atuação do Organismo.

\section{MARCOS TEÓRICOS SOBRE CORRUPÇÃO: TEORIAS, PERSPECTIVAS E DESAFIOS}

A tarefa de conceituar corrupção impõe o enfrentamento de óbices, máxime em se tratando de fenômeno sócio-político multifário, com diversificadas formas de manifestação no tempo e espaço. Por muitas décadas houve quem sustentasse que a corrupção seria monopólio de épocas ou regiões, com larga preponderância em países subdesenvolvidos/periféricos e anteriormente às modernizações (WEBER, 2004).

Na literatura especializada, Graaf (2007, p.39) pontua que, apesar dos múltiplos casos de corrupção pelo mundo, o tema ainda tem sido pouco estudado como agenda de pesquisa: "there are not many studies on actual, individual corruption cases. It seems, therefore, that we need more contextual corruption research"3. Autores comungam da opinião de que a pesquisa científica sobre a temática possui poucas certezas, muitas dúvidas e resultados inconclusivos, exatamente o oposto do verificado nos debates públicos (HOUGH, 2013; JOHNSTON, 2013; HOLMES, 2015).

A mesma conclusão é compartilhada por Filgueiras (2009), ao constar a existência de vertentes interpretativas no pensamento político e social brasileiros sobre patrimonialismo e uma inclinação do brasileiro a práticas imorais na esfera pública, sem preocupação com a formulação de uma teoria geral de cunho interpretativo abrangente sobre a corrupção, assunto deixado de lado em reflexões acadêmicas por muitas décadas.

As concepções clássicas do fenômeno da corrupção situam-no como degeneração de formas ideais ou puras de governo (monarquia, aristocracia e democracia). Logo, ser-lhe-iam inerentes as ideias de perda de propriedades constitutivas de regimes e descaracterização

${ }^{3}$ Em tradução livre: "não há muitos estudos sobre atuais e individuais casos de corrupção. Parece, portanto, que precisamos de mais pesquisas sobre o contexto da corrupção". 
ontológica de estruturas políticas. De toda sorte, cuidar-se-ia de problema estatal afeto à órbita das formas de governo.

À questão sobre eventual traço essencial inerente a todas as manifestações corruptas, Klitgaard (1994, p. 38) responde descrevendo núcleos imprescindíveis à configuração de um ato de corrupção, ao conceituá-la como a "indução por meio de considerações impróprias ao cometimento de uma violação de dever". Logo, trata-se de comportamento que se desvirtua dos deveres formais de uma função pública devido a interesses privados (pessoais, familiares ou de grupo fechado) de natureza pecuniária ou mesmo extrapatrimonial.

Holmes (2015, p. 22) também esclarece que a palavra corrupção derivaria do latim, significando algo que estraga, polui, abusa ou destrói, aludindo inicialmente a estágio de impureza moral. Com o passar do tempo, o conceito passou por ressignificações e tem sido usado no tempo presente "to describe any deviation from the norm that is considered improper.(...) the term nowadays refers primarily to improper behaviour linked to one's official position". 4

Bobbio, Matteucci e Pasquino (1998, p. 291-293) descreveram o verbete corrupção na seguinte forma no Dicionário de Política, caracterizando-a como fator de desagregação do sistema e vinculando-a a elementos como o grau de institucionalização, amplitude dosetor público, ritmo das mudanças sociais e cultura das elites e dasmassas, a saber:

\footnotetext{
Assim se designa o fenômeno pelo qual um funcionário público é levado a agir de modo diverso dos padrões normativos do sistema, favorecendo interesses particulares em troco de recompensa. Corrupto é, portanto, o comportamento ilegal de quem desempenha um papel na estrutura estadual.

(...)

Em conclusão: a Corrupção, ora surja em um sistema em expansão e não institucionalizado, ora atue em um sistema estável e institucionalizado, é um modo de influir nas decisões públicas que fere no íntimo o próprio sistema. De fato, este tipo privilegiado de influência, reservado àqueles que possuem meios, muitas vezes só financeiros, de exercê-la, conduz ao desgaste do mais importante dos recursos do sistema, sua legitimidade.
}

No entanto, Filgueiras (2008a) esclarece que o conceito de corrupção não se resume aos interesses dos agentes que a praticam, nem mesmo às normas jurídicas do ordenamento político, assumindo caráter plástico que somente poderá ser determinado no contexto linguístico em que os juízos são engendrados. Todavia, afigura-se razoável entender, com

\footnotetext{
${ }^{4}$ Em tradução livre: "para descrever qualquer desvio da norma que seja considerado impróprio. (...) hoje em dia o termo refere-se, primordialmente, a comportamentos inapropriados por parte de quem mantém uma posição oficial" (HOLMES, 2015, p.22).
} 
supedâneo na concepção habermasiana de moralidade, tratar-se o fenômeno em tela de violação de expectativas normativas agasalhadas em preceitos deliberados de forma consensual na esfera pública.

Heidenheimer, Johnston e LeVine (1989) enfrentaram a questão da percepção da corrupção como elemento valorativo e não descritivo, ao não dissociá-la da indignação e expectativa de sanções que provoca no tecido social. Nesse sentido, instituiu popular classificação dos atos de corrupção: i) corrupção negra: deriva de consenso das elites com a opinião pública na reprovação de determinado comportamento como merecedor de punição; ii) corrupção cinzenta: setores das elites vislumbram determinado comportamento como merecedor de punição, com dissenso também na opinião pública; e iii) corrupção branca: larga maioria da elite e da opinião pública entendem determinado comportamento como tolerável.

No mesmo esforço de sistematização, Michael Johnston (2005) classifica os atos de corrupção em quatro síndromes, que poderão ser encontrados isolada ou cumulativamente em países desenvolvidos e subdesenvolvidos: i) mercados de influência (influence markets), inerentes às democracias consolidadas e com instituições sólidas, representados por práticas como os lobbies, financiamentos de campanhas eleitorais e tráficos de influência; ii) cartéis de elite (elite cartels), destinados à manutenção e proteção de elites em países de recente democratização diante de novos desafios político-econômicos; iii) oligarquias e clãs (oligarchs and clans), presentes em países de instituições frágeis que sofreram com bruscas liberalizações político-econômicas, nos quais pequena quantidade de oligarcas absorvem as riquezas; e iv) magnatas oficiais (official moguls), representados pelos burocratas que cobram propina e vantagens de quem precisa do governo, em países de instituições frágeis e sem oportunidades democráticas na economia.

As teorias funcionalistas da corrupção associam-na mais diretamente às questões da modernização e do desenvolvimento, buscando compreender o modo como poderia contribuir ou obstaculizar o crescimento de sociedades tradicionais e subdesenvolvidas. Para Huntington (1975), haveria uma relação necessária entre corrupção e modernização, tendo em vista que cenários de larga corrupção definiriam baixa institucionalização política e uma ordem fraca para resolução de conflitos.

$\mathrm{Na}$ perspectiva funcionalista, que se tornou dominante na década de 1960, o fenômeno seria típico, embora não exclusivo, de sociedades subdesenvolvidas. Mas se 
mantida sob controle de instituições modernas, a corrupção poderia assumir uma função no desenvolvimento de países subdesenvolvidos, pois se revestiria como alternativa a agentes empresariais para articularem interesses do capital na esfera pública (FILGUEIRAS, 2009).

Dessa forma, ainda que paradoxalmente cogitada como disfuncionalidade do sistema, a corrupção cumpriria papel funcional na agilização da burocracia, aceleração da emissão de documentos e autorizações formais por parte do Estado, azeitando o desenvolvimento econômico ao estabelecer laços informais entre burocratas e investidores privados (LEFF, 1964).

No Brasil, a teoria da modernização abeberou-se nessa matriz funcionalista, a partir de intérpretes consagrados das questões nacionais, como Sérgio Buarque de Holanda (2014) e Raymundo Faoro (2012), ambos com formação mais acentuadamente histórico-sociológica. Segundo Filgueiras (2008b), a teoria da modernização centra-se no conceito de patrimonialismo, predominando até os anos de 1990, arrimando-se em concepções weberianas sobre legitimidade da dominação, partindo de epistemologia fundada na compreensão de fatos sociais a partir da concepção de modelos ideais.

Parra a corrente, a noção basilar de patrimonialismo consistiria em arranjo institucional pré-moderno com predomínio de relações de dominação legitimadas pela tradição (arcaicas), em contraposição à dominação ideal moderna, marcada pela racionalidade legal. Opor-se-iam as dimensões da moralidade pública (macro), marcada pelos valores da modernidade, com a moralidade privada (micro), na qual estariam contemplados os valores individuais (FILGUEIRAS, 2008b).

Segundo Holanda (2014), em razão das culturas da personalidade e da cordialidade, estruturadas a partir de relações orgânicas e comunais (parentesco, amizade e vizinhança), os detentores de poder no Estado brasileiro possuiriam verdadeiras dificuldades de discernir as raias entre o público e o privado no estágio inicial de evolução das instituições e dos costumes políticos, cujo ponto culminante seria o funcionamento de uma burocracia profissional e especializada.

Desse modo, exsurge a noção de homem cordial como representativa do comportamento dos indivíduos no contexto de formação da sociedade brasileira, bem como a ideia da cordialidade como traço definidor do caráter brasileiro, oriundo do patriarcalismo privatizador do poder,segundo o qual o indivíduo imporia supremacia sobre o social, razão 
pela qual sem aptidão para formação de uma ordem pública racional, impessoal e democrática (HOLANDA, 2014).

A teoria da modernização, além de associar a corrupção ao subdesenvolvimento, vinculando a sua erradicação à busca pelo desenvolvimento, fomenta discurso de prevenção de comportamentos corruptos através da criação de códigos de conduta (deontológicos), promoção de treinamentos de formação ética para eliminação do clientelismo/nepotismo e implantação da meritocracia na Administração Pública.

De outro turno, a agenda de pesquisa preponderante a partir da década de 1990 nos estudos sobre corrupção adota a teoria do neoinstitucionalismo econômico, centrado no conceito de rent-seeking (busca de renda), corrente inaugurada com a publicação de Corruption: a Study in Political Economy, de Susan Rose-Ackerman (FILGUEIRAS, 2008b).

O papel desbravador da obra de Ackerman (1978) nos estudos sobre o fenômeno da corrupção decorreria do rechaço, embasado em cálculos racionais, aos supostos efeitos benéficos da corrupção para as relações econômicas, em desarticulação à metáfora funcionalista que a equiparava a uma "graxa" ou "azeite" com propriedades adequadas para lubrificação das engrenagens da economia (ABRAMO, 2005, p. 34):

Em 1978, Susan Rose-Ackerman publicou seu Corruption: a study in political economy em que argumenta que o papel e o impacto da corrupção sobre a economia e as organizações políticas são mais extensos e profundos do que até então se sustentava. O surgimento do trabalho de Rose-Ackerman foi um divisor de águas. A partir daí, declinou a popularidade da interpretação da corrupção como lubrificante benéfico para a economia e se passou a prestar mais atenção aos prejuízos que ela traz à eficiência econômica.

O neoinstitucionalismo parte de concepção hobbesiana da natureza humana, tendo como pressuposto o racionalismo econômico, através do qual caberia aos homens a tomada de decisões por julgamentos amorais, orientandos exclusivamente pelo auto-interesse egoísta e baseado no utilitarismo em suas relações econômicas, sociais e políticas.

Perspectiva mais radical do neoinstitucionalismo econômico cogita, inclusive, que não haveria decisões coletivas que derivassem de verdadeiro interesse coletivo, uma vez que todas as decisões coletivas deveriam ser entendidas como resultantes de um universo de interesses individuais dos agentes envolvidos e interessados (FILGUEIRAS, 2008b).

$\mathrm{O}$ conceito de rent-seeking reveste-se de significado relevante. Nas ciências econômicas, é empregado para descrever o desequilíbrio nas relações econômicas provocado por agentes que buscam a riqueza e acumulação de capital não pelas vias ordinárias do 
capitalismo, através da agregação de valor de produtos/mercadorias ou mesmo pela adequada mensuração das leis da oferta/procura. Designa a prática de agentes econômicos que intentam enriquecer com subsídios, monopólios, lobbies, apadrinhamentos, sinecuras e privilégios do Estado, em manipulação do ambiente político e social (PASOUR JR., 1987).

No campo da corrupção, rent-seeking permite a compreensão da corrupção como um comportamento oportunista e arrivista de sujeitos amorais e sequiosos por facilidades, que se manifesta por meio de ações ilegais voltadas a propiciar transferência de renda ou aquisição de vantagens ilícitas que atendam a interesses particulares em detrimento do interesse público.

A corrupção resultaria de configurações institucionais e do modo como permitiriam que agentes egoístas autointeressados maximizassem seus lucros e ganhos em burla às regras do sistema político. Poderia ser explicada como ação imoral calculada que agentes racionais fariam de custos e benefícios derivados da burla de regras institucionalizadas (ACKERMAN, 1978).

Incentivos propiciados por redes de privilégios decorrentes de arranjos institucionais falhos, que permitiriam a existência de monopólios estatais, excesso de discricionariedade na condução de negócios públicos e mecanismos inadequados ou insuficientes de accountability constituem as principais causas da corrupção (KLITGAARD, 1994).

$\mathrm{Na}$ clássica lição dos Federalist Papers sobre natureza humana, separação de poderes e constituição mista de governo, sob influência do ideário hobbesiano, não sendo os homens anjos ou governados por anjos, tratando-se de governo administrado por homens e para homens, há de ser aquele subordinado a controles externo e interno (HAMILTON; JAY; MADISON, 2001, p. 269):

If men were angels, no government would be necessary. If angels were to govern men, neither external nor internal controls on government would be necessary. In framing a government which is to be administered by men over men, the great difficulty lies in this: you must first enable the government to control the governed; and in the next place oblige it to control itself. ${ }^{5}$

A propósito, Klitgaard (1994) notabilizou-se pela engenhosa formulação de equação para compreensão do fenômeno da corrupção pública: C=M+D-A. Em tradução livre, a corrupção seria o resultado do monopólio (monopoly), mais a discricionariedade de agentes

\footnotetext{
${ }^{5}$ Em tradução livre: "Se homens fossem anjos, nenhum governo seria necessário. Se anjos governassem homens, nenhum controle externo ou interno sobre o governo seria necessário. Ao organizar um governo que tem de ser administrado por homens para homens, a grande dificuldade está nisso: você tem de primeiro habilitar o governo a controlar os governados, e em seguida, obrigá-lo a controlar a si mesmo".
} 
públicos (discretion), inversamente proporcionais à responsabilização/transparência (accountability).

A significação pragmática desse modelo econômico apontaria para a ilação de que os benefícios e custos potenciais do agente poderiam ser afetados direta e decisivamente pela política e gestão públicas, de modo que existirá ambiência desfavorável à corrupção quando benefícios líquidos potenciais não superarem os custos da atividade (KLITGAARD, 1994).

A teoria do neoinstitucionalismo econômico posiciona o papel da responsabilização pública das instituições como vacina contra a corrupção, sublinhando a convicção de que as atividades de controle e transparência ser-lhe-iam inversamente proporcionais, em superação ao paradigma fatalista da inexorável intransponibilidade do patrimonialismo, prestigiando a magnitude de ferramentas institucionais dissuasórias das mencionadas práticas ilícitas.

Jorge Malem Seña $(2014$, p. 178) posiciona-se sobre o fatalismo catastrofista e a suposta inevitabilidade da corrupção nas sociedades, discernindo ocorrências naturais inevitáveis de atos humanos voluntários e, portanto, evitáveis a partir de desenhos institucionais e consensos entre elites governamentais e cidadãos:

\begin{abstract}
Alguien podría decir que debido precisamente a su universalidad la corrupción es un fenómeno inevitable, es una catástrofe. Pero las catástrofes son acontecimientos naturales cuya ocurrencia y cuyos efectos no dependen de la voluntad de las personas. Su existência va unida a una cierta idea de la fatalidad. Pero la corrupción no es una catástrofe natural es, muy por el contrario, una calamidad que depende de acciones humanas y es, por lo tanto, algo evitable. Eso dependerá del diseño institucional que se adopte y de su aceptación por parte de las elites gobernantes y de los ciudadanos ${ }^{6}$.
\end{abstract}

Por conseguinte, inobstante as apontadas vicissitudes epistemológicas para a pesquisa de corrupção pelas ciências sociais, impõe-se divisar que constitui fenômeno político concernente à gestão do poder, cujo enfrentamento desafia povos e gerações na história da humanidade.

Para além da retórica infecunda que a consagra a corrupção como vetusta bandeira discursiva de forças em disputa nos regimes democráticos, e dos fatalismos moralistas

\footnotetext{
${ }^{6}$ Em tradução livre: "Alguém poderia dizer que, precisamente por causa de sua universalidade, a corrupção é um fenômeno inevitável, é uma catástrofe. Mas as catástrofes são eventos naturais cuja ocorrência e cujos efeitos não dependem da vontade do povo. Sua existência está ligada a uma certa ideia de fatalidade. Mas a corrupção não é uma catástrofe natural, pelo contrário, é uma calamidade que depende das ações humanas e, portanto, é algo evitável. Isso dependerá do desenho institucional adotado e de sua aceitação pelas elites dominantes e pelos cidadãos".
} 
interessados que espraiam as ideologias da catástrofe e da sua inevitabilidade, vislumbra-se que o traço da voluntariedade afigura-se-lhe inolvidável, de sorte a restar esperançosamente renovado o desafio sempiterno de que há construto antrópico viável para a elaboração coletiva de ordem política esculpida sob as notas da boa governança pública e da probidade.

\section{TUTELA CONVENCIONAL DO COMBATE À CORRUPÇÃO}

\subsection{Escala Planetária do Combate à Corrupção}

Tendo em vista que a corrupção consiste em fenômeno de escala planetária, desafiador de fronteiras e de limites territoriais, surgiram no final do século XX instrumentos internacionais destinados a prevenir e erradicá-la. A experiência dos países com os casos concretos evidenciou a insuficiência dos esforços domésticos para a contenção das práticas ímprobas, de sorte a ser almejada a cooperação multilateral.

O pressuposto dos acordos multilaterais e supranacionais é de que os Estados reconhecem a gravidade dos problemas e das ameaças decorrentes da corrupção para a estabilidade e a segurança das sociedades, temendo o enfraquecimento das instituições e dos valores da democracia, da ética e da justiça.

Ademais, os instrumentos internacionais de combate à corrupção sinalizam a preocupação dos Estados Nacionais com os vínculos entre a corrupção e outras formas de delinqüência, em particular o crime organizado e a lavagem de dinheiro, bem como com a larga pulverização das práticas corruptivas, que penetram diversos setores da sociedade, com potencial de comprometimento de proporçõesvultosas dos recursos estatais, ameaçando a estabilidade política e o desenvolvimento sustentável.

Aludidos diplomas internacionais também compreendem que a corrupção deixou de ser um problema local para converter-se em um fenômeno transnacional que afeta todas as sociedades e economias, afigurando-seimprescindível a cooperação internacional para prevenir e erradicá-la.

Essas tarefas são tomadas como responsabilidades de todos os Estados Nacionais signatários dos instrumentos, os quais deverão cooperar entre si, com o apoio e a participação de pessoas e grupos que não pertencem ao setor público, como a sociedade civil, as 
organizações não-governamentais e as organizações de base comunitárias, para que os esforços envidados sejam plenamente eficazes (BRASIL, 2006).

Por ordem cronológica, surgiram a Convenção Interamericana contra a Corrupção da OEA (1996), a Convenção sobre o Combate da Corrupção de Funcionários Públicos Estrangeiros em Transações Comerciais Internacionais da OCDE (1997), a Convenção relativa à Luta contra a Corrupção de Funcionários das Comunidades Europeias ou dos Estados-membros da União Europeia (1997), o Convênio sobre a Luta contra o Suborno dos Funcionários Públicos Estrangeiros nas Transações Comerciais Internacionais, aprovado pelo Comitê de Ministros do Conselho Europeu (1999); o Convênio de Direito Civil sobre a Corrupção, aprovado pelo Comitê de Ministros do Conselho Europeu (1999); e a Convenção da União Africana para Prevenir e Combater a Corrupção, aprovada pelos Chefes de Estado e Governo da União Africana (2003).

\subsection{Convenção Interamericana contra a Corrupção (1996)}

Em 1994, os Ministros das Relações Exteriores da América e os Chefes de Delegação dos Estados Membros da Organização dos Estados Americanos (OEA) assinaram a Declaração de Belém do Pará, manifestando apoio a estudos de medidas de combate à corrupção, de melhoria da eficiência da gestão pública e de promoção da transparência e probidade da administração pública. Assim, a Assembleia-Geral da OEA determinou ao Conselho Permanente o estabelecimento do Grupo de Trabalho sobre Probidade e Ética, através da Resolução AG/RES 1294 (MEYER-PFLUG; OLIVEIRA, 2009).

Após as atividades do citado grupo de trabalho, a Convenção Interamericana contra a Corrupção foi subscrita em Caracas (Venezuela), em 29 de março de 1996, no âmbito da Organização dos Estados Americanos (OEA), tendo sido aprovada pelo Congresso Nacional através do Decreto-Legislativo $n^{\circ} 152 / 2002$ e posteriormente introduzida no ordenamento jurídico brasileiro pelo Decreto Federal no 4.410/2002 (BRASIL, 2002).

Sagrou-se como o instrumento internacional pioneiro destinado a coibir as práticas ímprobas que viabilizaram a prática da corrupção transnacional, propiciadas pela globalização econômica das últimas três décadas. O aumento dos negócios transfronteiriços e as frequentes situações nas quais funcionários públicos interagem com investidores e empresários 
internacionais, em transações que envolvem quantias milionárias, suscitaram mais oportunidades para subornos e negociatas (RAMINA, 2009).

Organizada em vinte e oito artigos, a Convenção Interamericana contra a Corrupção engendrou conceituação e tipificação de um amplo elenco de atos corruptos, incluindo a corrupção passiva e ativa, doméstica e transnacional, em rol não taxativo, servindo como parâmetro para todos os diplomas posteriores acerca da matéria.

Em apertada síntese, referido instrumento estabelece no preâmbulo os princípios regentes do combate à corrupção, os objetivos e propósitos da norma convencional (art. II), medidas preventivas para evitar os desvios (art. III), exemplificação de atos de corrupção (arts. VI e XI), censura ao suborno transnacional (art. VIII), a exortação à tipificação do enriquecimento ilícito como delito nos ordenamentos nacionais (art. IX), regras de extradição, assistência e cooperação internacional em atos de corrupção transnacionais (arts. XIII, XIV, XV e XVI), designação de autoridades centrais para implementação da norma convencional (art. XVIII) e a não exclusividade da norma convencional no combate à corrupção (art. XX).

No Brasil, destaca-se que ainda não foi efetuada a criminalização do enriquecimento ilícito de agentes públicos, embora já existente a tipificação da conduta como ilícito civil no art. $9^{\circ}$ da Lei de Improbidade Administrativa (Lei Federal n ${ }^{\circ}$ 8429/1992). Todavia, persiste ineficaz o comando estabelecido no art. IX da Convenção Interamericana contra a Corrupção (MEYER-PFLUG; OLIVEIRA, 2009).

No dizer de Ramina (2009), a Convenção da OEA representa um grande e inovador avanço na esfera internacional para o combate da corrupção, tendo sido responsável por abrir caminho para a celebração de tratado anticorrupção com vocação universal no âmbito da Organização das Nações Unidas (ONU).

\subsection{Convenção Relativa à Luta contra a Corrupção de Funcionários das Comunidades} Europeias ou dos Estados-membros da União Europeia (1997)

No título VI do Tratado da União Europeia - Tratado de Maastricht (Disposições Relativas à Cooperação Policial e Judiciária em Matéria Penal), o artigo $29^{\circ}$ refere-se expressamente à prevenção e ao combate contra a corrupção, organizada ou não, como um dos objetivos para a criação e a salvaguarda de um espaço europeu de liberdade, segurança e 
justiça, através de uma cooperação judiciária, policial e aduaneira mais estreita e, quando pertinente, da aproximação da legislação penal.

Aprovada através do Ato do Conselho da União Europeia, de 26 de maio de 1997, foi antecedida por estudo endereçado ao Conselho, ao Parlamento Europeu e ao Comitê Econômico e Social Europeu sobre uma política global da União Europeia contra a corrupção, elaborado em 28/05/2003 pela então Comissão das Comunidades Europeias.

Contém o referido estudo fundamentadora previsão do compromisso político prioritário da União Europeia com a erradicação da corrupção, da aplicação efetiva de instrumentos de cooperação em matéria penal, da criação de uma cultura anticorrupção nas instituições comunitárias, da prevenção da corrupção no âmbito nacional e supranacional e da adoção do combate à corrupção na agenda externa da UE.

A Convenção Relativa à Luta contra a Corrupção de Funcionários das Comunidades Europeias ou dos Estados-membros da União Europeia (1997) considerou a luta contra a corrupção questão de interesse comum abrangida pela cooperação instituída pelo Tratado da União Europeia.

Também assinalou a perspectiva de melhorar a cooperação judiciária em matéria penal entre osEstados-membros, para além do protocolo aprovado pelo Ato do Conselho de 27/09/1996, dispondo como objeto os atos de corrupção em que estejam implicados funcionários das Comunidades Europeias ou dos Estados-membros.

Em síntese, os mais importantes dispositivos do instrumento em tela dispõem sobre a conceituação de funcionários nacional e comunitário (artigo $1^{\circ}$ ), a tipificação da corrupção passiva, ativa e equiparações, com determinação para criminalização das condutas nos ordenamentos nacionais (artigos $2^{\circ}, 3^{\circ}$ e $4^{\circ}$ ), a recomendação de sanções (artigo $5^{\circ}$ ), a responsabilidade penal dos dirigentes de empresas (art. $6^{\circ}$ ), regras de competência, extradição, processamento e cooperação (artigos $7^{\circ}, 8^{\circ}$ e $9^{\circ}$ ), regra da proibição do bis in idem (art. $10^{\circ}$ ), compatibilização com as previsões de direito interno (artigo $11^{\circ}$ ) e atribuições do Tribunal de Justiça (artigo 12).

\subsection{Convenção das Nações Unidas contra a Corrupção (2003)}

A Convenção das Nações Unidas contra a Corrupção (Convenção da ONU de 2003) foi assinada em 15 de dezembro de 2003, na cidade de Mérida, no México, aprovada pelo 
Decreto Legislativo no 348/2005 e promulgada através do Decreto Federal no 5.687, de 31 de janeiro de 2006. Tal diploma objetiva um combate universal e sem fronteiras pelos Estados contra a corrupção (MEYER-PFLUG; OLIVEIRA, 2009).

Encartou como objetivos os seguintes: a) promoção e fortalecimento das medidas para prevenir e combater mais eficaz e eficientemente a corrupção; b) promoção, facilitação e apoio à cooperação internacional e à assistência técnica na prevenção e na luta contra a corrupção, incluída a recuperação de ativos; e c) promoção da integridade, da obrigação de render contas e a devida gestão dos assuntos e dos bens públicos (BRASIL, 2006).

Além de reafirmar dispositivos já previstos na Convenção Interamericana contra a Corrupção (1996), a exemplo da criminalização do enriquecimento ilícito, a Convenção das Nações Unidas contra a Corrupção trouxe, no dizer de Meyer-Pflug e Oliveira (2009), as seguintes diretrizes: i) necessidade de órgãos de prevenção contra práticas de corrupção pelos países signatários (artigo 6); ii) importância do princípio da eficiência no setor público (artigo 7); iii) elaboração de códigos de conduta para funcionários públicos (artigo 8); e iv) participação da sociedade civil, das organizações governamentais e das organizações com base na comunidade na prevenção e luta contra a corrupção (artigo 13).

Destaca-se, outrossim, a previsão de dispositivos alusivos à contratação pública e gestão da fazenda pública (artigo 9), transparência da Administração através de informações públicas (artigo 10), medidas para garantia da idoneidade e independência dos membros do Poder Judiciário e do Ministério Público (artigo 11), combate à corrupção no setor privado (artigo 12), prevenção da lavagem de dinheiro (artigo 14), responsabilização das pessoas jurídicas (artigo 26), proteção dos denunciantes (artigo 33), ressarcimento civil pelos danos e prejuízos causados por práticas corruptas (artigo 35) e recuperação de ativos (artigo 51).

$\mathrm{Na}$ avaliação do governo brasileiro, através do Ministério da Transparência, Fiscalização e Controladoria-Geral da União (CGU), órgão especializado no controle interno e combate à corrupção, medidas estão sendo tomadas para implementação da Convenção das Nações Unidas contra a Corrupção (BRASIL, 2017), a saber:

O Brasil está fortalecendo as suas instituições responsáveis pela prevenção e combate à corrupção e adequando sua legislação para que essa sirva como efetivo instrumento de repressão desse delito. A Controladoria-Geral da União (CGU), desde que foi criada, vem realizando seguidas ações de auditoria e apuração de fraudes e desvios de recursos, algumas, inclusive, em parceria com a Polícia Federal, com o Ministério Público Federal e com os Ministérios Públicos dos Estados.

Além disso, a CGU vem desempenhando funções típicas de uma agência anticorrupção. Nesse contexto, também estão sendo desenvolvidas estratégias e políticas de prevenção e combate à corrupção. Devido a sua destacada atuação, a 
CGU está caminhando para se tornar um órgão de referência da ONU no combate à corrupção para os países do continente, como já anunciado pelo Escritório das Nações Unidas contra Drogas e Crime (UNODC) no Brasil.

No que se refere à legislação, podemos destacar o envio de dois projetos de lei ao Congresso Nacional. O primeiro prevê a inclusão do artigo 317-A ao Código Penal, instituindo o crime de Enriquecimento Ilícito. O segundo é o projeto de lei que prevê situações que configuram o Conflito de Interesses e institui a nova "quarentena" no Poder Executivo Federal. Além disso, está sendo finalizado o Anteprojeto de Lei de Acesso à Informação.

\section{EXPERIÊNCIA DO ORGANISMO EUROPEU DE LUTA ANTIFRAUDE - OLAF}

A União Europeia teve aprovado como orçamento anual no exercício de 2016 as quantias de 155 bilhões de euros para autorizações e 143 bilhões de euros para pagamentos. Em 2015 foi divulgada estimativa de que cerca de 120 bilhões de euros tenham sido desviados em razão de práticas de corrupção, o que equivale a 1,04\% do Produto Interno Bruto (PIB) do bloco (COMISSÃO EUROPEIA, 2016).

$\mathrm{O}$ orçamento da UE destina-se a apoiar financeiramente programas, projetos e serviços públicos e/ou privados que fomentem a qualidade de vida dos cidadãos europeus e até mesmo do restante do mundo. Assim, a utilização fraudulenta e abusiva das verbas orçamentárias, ou mesmo a evasão do pagamento de tributos e quotizações, que as constituem, lesam diretamente a cidadania e o projeto supranacional europeu.

Por tal razão, a União Europeia instituiu em 28/04/1999 o Organismo Europeu de Luta Antifraude, do francês Office de Lutte Anti-Fraude (OLAF), destinado ao exercício das atribuições da Comissão em matéria de inquéritos administrativos, com o fim de reforçar a luta contra a fraude, corrupção e quaisquer outras atividades ilegais lesivas aos interesses financeiros da União, bem como para efeitos da luta antifraude pertinente a qualquer outro fato ou atividade de operadores em violação de disposições comunitárias.

É dizer, o OLAF é o centro especializado de competências investigatórias de casos de fraude, corrupção e outras atividades ilegais, que apura faltas profissionais graves do pessoal das instituições europeias e ajuda a Comissão Europeia na definição e implementação de políticas para prevenir e identificar fraudes no âmbito da UE.

As atribuições do OLAF também compreendem a realização de entrevistas e inspeção de instalações, bem como a articulação, coordenação e acompanhamento de diligências de organismos nacionais de luta antifraude/corrupção, a recomendação de medidas às instituições da UE e aos governos nacionais em causa (investigações criminais, ações 
penais, recuperações financeiras ou outras medidas disciplinares), bem ainda o controle da implementação de suas recomendações (EUROPEAN UNION, 2015).

Logo, além dos poderes de investigação, sobrelevam as atribuições recomendatórias do OLAF, interlocutor direto das autoridades policiais e judiciárias nos assuntos de sua competência, nos domínios financeiro, disciplinar, administrativo e até judicial, a partir dos inquéritos instaurados e conduzidos pelo organismo, composto por 435 colaboradores, dos quais dois terços atuam em atividades finalísticas (COMISSÃO EUROPEIA, 2016).

Para o desempenho de suas atribuições com independência, é vedado aos dirigentes e membros do OLAF solicitarem ou aceitarem instruções da Comissão, de qualquer Governo ou de qualquer outra instituição, órgão ou organismo. Segundo a Decisão da Comissão Europeia de 27/09/2013, o comando do Organismo é feito por um Diretor-Geral, designado pela Comissão para mandato de 07 anos, sem recondução, após concertação com o Parlamento e o Conselho (EUROPEAN UNION, 2015).

Os inquéritos levados a cabo pelo OLAF obedecem aos regramentos contidos no Regulamento $n^{\circ} 1073$, de 25/05/1999, do Parlamento Europeu e do Conselho da União Europeia, o qual ratifica o objetivo e funções do Organismo (art. $1^{\circ}$ ) e disciplina a instauração dos inquéritos administrativos, externos e internos (artigos $2^{\circ}, 3^{\circ}$ e $\left.4^{\circ}\right)$.

Referido regulamento menciona o reforço da luta contra a fraude, corrupção e todas as outras atividades ilegais lesivas dos interesses da União Europeia, devendo o OLAF exercer as competências de inquérito atribuídas à Comissão pelas normas em vigor nos citados domínios, bem como prestar apoio aos Estados-Membros para organizar colaboração com vistas à proteção dos interesses financeiros da UE contra a fraude (COMISSÃO EUROPEIA, 2016).

$\mathrm{O}$ regulamento estabelece requisitos para abertura dos inquéritos (artigo $5^{\circ}$ ), os procedimentos para processamento do inquérito (artigo $6^{\circ}$ ), os deveres de informação, confidencialidade e proteção de dados $\left(\operatorname{artigos} 7^{\circ}\right.$ e $8^{\circ}$ ), os requisitos e a força probante dos relatórios nos inquéritos (artigo $9^{\circ}$ ), o fornecimento e intercâmbio de informações com outras autoridades e instituições (artigo $10^{\circ}$ ) e as atribuições correicionais do Comitê de Fiscalização (artigo $11^{\circ}$ ).

Os procedimentos do OLAF têm as naturezas jurídicas de i) inquéritos internos: realizados dentro das instituições e organismos da União Europeia para apurar casos de fraude, corrupção ou outras atividades ilegais que sejam lesivos dos interesses financeiros da 
União Europeia, incluindo fatos graves ligados ao exercício de atividades profissionais; ii) inquéritos externos: realizados fora das instituições e organismos da União Europeia para detectar casos de fraude ou outros comportamentos irregulares por parte de pessoas singulares ou coletivas, desde que o OLAF seja responsável pela maior parte das investigações; e iii) processos de coordenação: consistem em contribuição para inquéritos conduzidos por autoridades nacionais ou por outros serviços da UE, facilitando a colheita e intercâmbio de dados e informações (EUROPEAN UNION, 2015).

Os relatórios anuais e as comunicações à Comissão exaram intensa atividade do OLAF desde a criação, com conclusão de mais de 1.400 inquéritos, condenação de mais de 335 pessoas à pena prisão, emissão de 1.600 recomendações e recuperação de cerca de 03 bilhões de euros ao orçamento da UE, uma média anual de 100 milhões de euros (COMISSÃO EUROPEIA, 2016).

\section{CONCLUSÃO}

A perspectiva contemporânea de prevenção e enfrentamento à corrupção com enfoque no fortalecimento de instituições torna o trabalho relevante, na medida em que quase inexistente bibliografia acerca da atuação do Organismo Europeu Antifraude (OLAF), que detém atribuições investigativas e recomendatórias para salvaguarda direta e indireta de fundos no âmbito da União Europeia.

Vislumbra-se que os esforços internacionais de estabelecer cooperação para prevenir e punir os malfeitos na área afiguram-se recentes, consubstanciados pelas convenções que surgiram após a década de 1990. Não bastasse isso, a delonga dos países em ratificá-las e darlhes fiel execução denota os incômodos e as resistências domésticas que as políticas públicas de promoção da transparência e de combate à corrupção suscitam.

A título de exemplificação, pontuou-se a recalcitrância da República Federativa do Brasil na criminalização do enriquecimento ilícito de agentes públicos, mesmo diante da tipificação da referida conduta como ilícito civil passível das sanções da Lei de Improbidade Administrativa (Lei Federal n 8.429/1992), bem como das exortações erigidas na Convenção Interamericana contra a Corrupção (1996) e na Convenção das Nações Unidas contra a Corrupção (2003). 
$\mathrm{O}$ estudo da realidade europeia desmistifica a perspectiva funcionalista de que a corrupção seria fenômeno exclusivo de países subdesenvolvidos e periféricos. Apesar dos balanços divulgados pelo OLAF com o resultado de operações, salta aos olhos a cifra dos prejuízos advindos de práticas de fraude e corrupção em detrimento do patrimônio da União Europeia, quase correspondente à totalidade do orçamento anual para pagamentos. Por tal razão a necessidade permanente de reavaliação das políticas (accountability), bem como os projetos para criação de uma Procuradoria Europeia, munida de atribuições persecutórias com o condão de agilizar os procedimentos de responsabilização.

Deve-se constatar que a atuação do OLAF constitui experiência singular de prevenção e repressão à corrupção no âmbito supranacional, dado o grau avançado de integração da União Europeia, inclusive em complementação às políticas dos Estados Nacionais com esse propósito. Iniciativa similar deveria ser, no mínimo, cogitada no âmbito dos blocos regionais e supranacionais dos quais o Brasil faz parte, como o G20, Mercosul e BRICs, em auxílio aos países que enfrentam os piores índices de transparência e integridade nos rankings internacionais.

Talvez haja dúvidas sobre as medidas mais adequadas no enfrentamento da corrupção em todos os níveis, dentre diversas condições de possibilidades acolhidas pela heterogeneidade dos modelos culturais existentes no mundo. Todavia, as bem sucedidas experiências comparadas e os modelos teóricos demonstram a necessidade de as instituições especializadas anticorrupção possuírem papel independente e sobranceiro, razão pela qual deverão ser estimuladas e aprimoradas, em fomento à boa gestão pública para afirmação dos direitos fundamentais da cidadania.

\section{REFERÊNCIAS}

ABRAMO, Cláudio Weber. Percepções pantanosas: a dificuldade de medir a corrupção. Revista Novos Estudos - Cebrap $\mathrm{n}^{\circ}$ 73, 2005. Disponível em: $<$ http://www.scielo.br/scielo.php?pid=S010133002005000300003\&script=sci_arttext\&tlng=pt>. Acesso em: 07 ago. 2018.

ACKERMAN, Susan Rose. Corruption: a study in political economy. New York: Academic Press, 1978.

BOBBIO, Norberto; MATTEUCCI, Nicola; PASQUINO, Gianfranco. Pasquino. Dicionário de política. 11.ed. Trad. Carmen Varriale et al. Brasília: Editora da Universidade de Brasília, 1998. 
BRANT, Leonardo Nemer Caldeira. A união européia e os estudos de integração regional. Belo Horizonte: Del Rey, 2009.

BRASIL. Decreto $\mathbf{n}^{\mathbf{0}}$ 4.410, de 07 de outubro de 2002. Promulga a Convenção Interamericana contra a Corrupção, de 29 de março de 1996. Disponível em:<http://www.planalto.gov.br/ccivil_03/decreto/2002/D4410.htm>. Acesso em: 10 jan. 2017.

Decreto $\mathbf{n}^{0}$ 5.687, de 31 de janeiro de 2006. Promulga a Convenção das Nações Unidas contra a Corrupção, adotada pela Assembléia-Geral das Nações Unidas em 31 de outubro de 2003 e assinada pelo Brasil em 9 de dezembro de 2003. Disponível em:<http://www.planalto.gov.br/ccivil_03/_ato2004-2006/2006/decreto/D5687.htm>. Acesso em: 10 jan. 2017.

União.
$\begin{aligned} & \text { Ministério da Transparência, Fiscalização e da Controladoria-Geral da } \\ & \text { Disponível }\end{aligned}$ em: $<$ http://www.cgu.gov.br/assuntos/articulacaointernacional/convencao-da-onu>. Acesso em: 10 jan. 2017.

Ministério Público Federal. Disponível em: <http://lavajato.mpf.mp.br/atuacao-na-1a-instancia/resultados/a-lava-jato-em-numeros-1>. Acesso em: 14 set. 2016.

CARVALHO, José Murilo de. Passado, presente e futuro da corrupção brasileira. In: AVRITZER, Leonardo; BIGNOTTO, Newton; GUIMARÃES, Juarez e STARLING, Heloisa (orgs). Corrupção. Ensaios e críticas. Belo Horizonte, Editora da UFMG, 2008.

CASTRO, Conceição. Determinantes econômicos da corrupção na União Europeia. Disponível em: <http://recipp.ipp.pt/bitstream/10400.22/6260/1/ART_ConceicaoCastro_2008_1.pdf.> Acesso em: 13 out. 2016.

COMISSÃO EUROPEIA. A luta da União Europeia contra a fraude e a corrupção no âmbito do Organismo Europeu de Luta Antifraude. Acesso em: <http://www.norte2020.pt/sites/default/files/public/uploads/documentos/LutaFraude.pdf.> Disponível em: 13 out. 2016.

CONTROLADORIA-GERAL DA UNIÃO. Auditoria e Controle Interno na União Europeia e no Brasil. Abril de 2015. Disponível em: <http://www.cgu.gov.br/Publicacoes/auditoria-e-fiscalizacao/arquivos/publicacao_seminariointernacional-de-auditoria-e-controle-interno.pdf>. Acesso em: 13 out. 2016.

CUNHA, Isabel Ferin. Da 'desdemocratização' da Europa: democracia, media e corrupção política. Intercom, Rev. Bras. Ciênc. Comun. [online]. 2015, vol.38, n.1, pp.3763. ISSN 1809-5844. <http://dx.doi.org/10.1590/1809-5844201512.> 
EUROPEAN UNION.The OLAF report 2015: Sixteenth report of the European AntiFraud Office, 1 January to 31 December 2015. Disponível em: <http://ec.europa.eu/antifraud/sites/antifraud/files/olaf_report_2015_en.pdf.>Acesso em: 13 out. 2016.

FAORO, Raymundo. Os donos do poder: formação do patronato político brasileiro. 5.ed. São Paulo: Globo, 2012.

FILGUEIRAS, Fernando. Corrupção, democracia e legitimidade. Belo Horizonte, UFMG, 2008a.

Marcos teóricos da corrupção. In: AVRITZER, Leonardo; BIGNOTTO, Newton; GUIMARÃES, Juarez e STARLING, Heloisa (orgs). Corrupção. Ensaios e críticas. Belo Horizonte, Editora da UFMG, 2008b.

.A tolerância à corrupção no Brasil: uma antinomia entre normas morais e prática social. Opinião Pública, Campinas, vol. 15, nº 02, 2009, p.386-421.

FONDEVILA, Manuel. La disolución de la soberania en el ámbito estatal: el proceso de integración europea. Madrid: Editora Reus, 2014.

FONSECA, Anderson Freitas da.O combate à corrupção sob a perspectiva internacional. Textos e Debates. Boa Vista, n.19, p. 31-45.

GARCIA, Emerson; ALVES, Rogério Pacheco. Improbidade administrativa. 8.ed. São Paulo: Saraiva, 2014.

GRAAF, Gjalt. Causes of corruption: towards a contextual theory of corruption. Public Administration Quarterly, $\mathrm{n}^{\mathbf{o}}$ 31, p.39-86,2007.

HAMILTON, Alexander; JAY, John; MADISON, James.The federalist. Indianapolis: Liberty Fund, 2001.

HEIDENHEIMER, Arnold; JOHNSTON, Michael; LEVINE, Victor. Political corruption: a handbook. New Brunswick: Transaction Books, 1989.

HOLANDA, Sérgio Buarque de. Raízes do Brasil. 27.ed. São Paulo: Companhia das Letras, 2014.

HOLMES, Leslie. Corruption: a very short introduction. Oxford: Oxford University Press, 2015.

HOUGH, Dan. Corruption, Anti-Corruption and Governance. Basingstoke: Palgrave Macmillan, 2013.

HUNTINGTON, Samuel Phillips. A ordem política nas sociedades em mudança. Rio de Janeiro: Forense Universitária, 1975. 
JOHNSTON, Michael. Syndromes of Corruption: Wealth, Power, and Democracy. Cambridge: Cambridge University Press, 2005.

Corruption, Contention and Reform: The Power of Deep Democratization.

Cambridge: Cambridge University Press, 2013.

KLITGAARD, Robert. A corrupção sob controle. Tradução de Octávio Alves Velho. Rio de Janeiro: Jorge Zahar Editor, 1994.

LEFF, Nathaniel H. Economic development through bureaucratic corruption.American Behavioral Scientist, Vol8, Issue 3, p. 8-14, 1964. Disponível em: <https://doi.org/10.1177/000276426400800303> Acesso em: 09 ago. 2018.

MEYER-PFLUG, Samantha Ribeiro; OLIVEIRA, Vitor Eduardo Tavares de. O Brasil e o combate internacional à corrupção. Revista de Informação Legislativa. Brasília a. 46 n. 181 jan./mar. 2009. p. 187/194.

PASOUR JR., E.C. Rent seeking: some conceptual problems and implications. Review of Austrian Economics, 1, pp. 123-145, 1987.Disponívelem: <https://mises.org/library/rentseeking-some-conceptual-problems-and-implications>. Acesso em: 14 set. 2016.

POLÍBIO. História. Livro VI. Trad. Mário de Gama Kury. Brasília: Editora da Universidade de Brasília, 1985.

RAMINA, Larissa. Tratamento jurídico internacional da corrupção. Revista de Direito da Universidade Federal do Paraná - 2009. p. 201/213. Disponível em: <http://revistas.ufpr.br/direito/article/view/1755/1452>. Acesso em: 10 jan. 2017.

SEÑA, Jorge Malem. La corrupción: aspectos éticos, económicos, políticos y jurídicos. Barcelona: Gedisa, 2002.

2014, p. 169-180.

.La corrupción: algunas consideraciones conceptuales. Revista Illes i imperis,

TRANSPARENCY INTERNATIONAL.Corruption Perceptions Index 2016.Disponível em: <https://www.transparency.org/news/feature/corruption_perceptions_index_2016\#table>. Acesso em: 20 ago. 2017.

.Corruption Perceptions Index 2017. Disponível em: <https://www.transparency.org/news/feature/corruption_perceptions_index_2017\#table>. Acesso em: 25 ago. 2018.

UNIÃO EUROPEIA. Decisão da Comissão Europeia de 27 de setembro de 2013. Disponível em: <http://eur-lex.europa.eu/homepage.html?locale=pt>. Acesso em: $10 \mathrm{fev}$. 2017.

.Decisão da Comissão Europeia de 28 de abril de 1999. Disponível em: <http://eur-lex.europa.eu/homepage.html?locale=pt>. Acesso em: 10 fev. 2017. 
.Regulamento no 1073/1999 do Parlamento Europeu e do Conselho da União Europeia. Disponível em: <http://eur-lex.europa.eu/homepage.html?locale=pt>. Acesso em: 10 fev. 2017.

WEBER, Max. A ética protestante e o espírito do capitalismo. Trad. José Marcos Mariani de Macedo. São Paulo: Companhia das Letras, 2004. 